\title{
Diagnosis of Autosomal Dominant Polycystic Kidney Disease In Utero and in the Young Infant
}

\author{
Dolores H. Pretorius, MD*, M. Eugenia Lee, MD*, Michael L. Manco-Johnson, MD*, \\ Gail R. Weingast, MD*, Aileen B. Sedman, MD†, Patricia A. Gabow, MD
}

Autosomal dominant polycystic kidney disease (ADPKD), once thought to be a disease of the adult, is now being reported with increasing frequency in childhood. We report five cases and review eight cases from the literature of ADPKD diagnosed in the fetus or the young infant by sonographic evaluation and a positive family history. Renal enlargement $(85 \%)$ was the most common and most helpful sonographic finding. Approximately $50 \%$ of the patients already had cysts large enough to detect by ultrasound. Increased renal echogenicity was present in nine of 10 cases. Although every case in this review had one parent affected with ADPKD, only five of $13(38 \%)$ were aware of their disease prior to their pregnancy Renal cystic disease diagnosed in the fetus and young infant should trigger an investigation of the family history and sonographic screening. KEY WORDS: kidney, ultrasound; fetus, kidney; neonate, kidney. (J Ultrasound Med 6:249, 1987)
A utosomal dominant polycystic kidney disease (ADPKD) - adult type - is one of the most common genetic disorders, occurring in one of every 500 autopsies, ${ }^{1}$ manifesting a penetrance of $100 \%$ beyond the age of 70 . The clinical course of the disease is usually one of progressive, asymptomatic enlargement of the kidneys with a gradual decline in renal function. ${ }^{2}$ Until recently, the disorder was believed to occur only in adults. ADPKD has now been reported in the fetus and newborn as well as in the juvenile and adult. ${ }^{3-18}$ The disease can become symptomatic in child hood and even in infancy. ${ }^{18}$ We report five cases of ADPKD diagnosed in the antenatal or neonatal period by sonographic eval-

Received July 11, 1986, from the 'Department of Radiology, University of Colorado Health Sciences Center, Denver, Colorado; the tDepartment of Pediatrics, University of Michigan Health Sciences Center, Ann Arbor, Michigan; and the $\ddagger$ Department of Medicine, University of Colorado Health Sciences Center, Denver, Colorado Revised manuscript accepted for publication November 18, 1986.

Address correspondence and reprint requests to Dr. Manco-johnson: Dept, of Radiology C277, 4200 E. Ninth Ave., Denver, CO 80262. uation and a positive family history. The purpose of this paper is to review the sonographic findings and the clinical cause, and to compare our findings to eight cases of sonographic evaluation of ADPKD in the fetus and young infant (birth through 3 months of age) in the literature.

\section{MATERIALS AND METHODS}

From 1979 to 1985 , five cases of ADPKD in a fetus or neonate $(<1$ month) were detected by ultrasonography. All of these cases had one parent positive for ADPKD. These cases were collected from four different medical institutions; two of these cases were examined at the University of Colorado Health Sciences Center. The technical aspects of the examinations varied, due to the fact that the cases were collected from several different sites. Images varied from real-time images only to a combination of static and real-time images.

Obstetrical sonograms were evaluated for gestational age, fetal renal size, renal appearance, amount of amni-

(c) 1987 by the American Institute of Ultrasound in Medicine $\bullet J$ Ultrasound Med 6:249-255, $1987 \bullet 0278-4297 / 87 / \$ 3.50$ 
otic fluid, fetal bladder, liver cysts, or other fetal anomalies. Renal enlargement was determined by the criteria set by Lawson. ${ }^{19}$

Neonatal sonograms were evaluated for renal size and appearance, presence or absence of cysts in the kidney and liver, and other anomalies. Renal enlargement was determined by criteria set by Han and Babcock. ${ }^{20} \mathrm{Clini}$ cal follow-up included birth outcome, sonograms when possible, and clinical renal function. Pathology by necropsy was available in two neonates in our series.

We reviewed published sonographic findings in eight cases of ADPKD in the fetus and neonate. All cases had a parent with ADPKD.

\section{CASE REPORTS}

Case 1 An obstetrical ultrasound was performed on a woman with ADPKD at 36 weeks' gestational age because of a positive family history of ADPKD. Approximately $11 / 2$ years previous to this examination, she delivered a child with no evidence of ADPKD. The sonogram revealed enlarged, very echogenic fetal kidneys: the right measured $5 \mathrm{~cm}$ AP by $5 \mathrm{~cm}$ width, and the left measured $5.8 \mathrm{~cm}$ AP by $5.5 \mathrm{~cm}$ width (normal, $2.0 \pm 0.3 \mathrm{~cm}$ ). A $3-\mathrm{cm}$ cyst occupied the left upper pole of the kidney (Fig. 1A). The fetal bladder was present, and amniotic fluid was normal in amount. No liver cysts or other fetal anomalies were visualized. Another obstetrical ultrasound was performed at 40 weeks' gestational age confirming the findings of the first examination. A normal vaginal delivery resulted in a term infant with congenital absence of the right hand. A neonatal sonogram performed at 8 days of age showed large, echogenic kidneys. The right kidney measured $6.2 \mathrm{~cm}$ in length and the left $8.1 \mathrm{~cm}$ in length. The cyst in the left upper pole measured $3.3 \mathrm{~cm}$ in diameter; no other renal cysts and no liver cysts were apparent. The initial serum creatinine concentration was increased, but returned to normal within $24 \mathrm{~h}$. The baby was mildly hypertensive and was treated with propranalol. A sonogram at 2 years of age revealed five cysts in the left kidney and five cysts in the right kidney. Both kidneys were still enlarged but were no longer dense. A sonogram performed at 4 years 10 months of age showed approximately 16 cysts involving bilaterally enlarged
Figure 1 Case 1. ADPKD. A, transverse scan through the uterus and the fetal abdomen at 36 weeks' gestational age. A $2.5 \mathrm{~cm}$ cyst (arrow) is seen in the left kidney. No cysts were seen in the enlarged echogenic right kidney. The spine (S) and placenta $(P)$ are noted. $B$, longitudinal scan through the right kidney at 4 years 10 months. Three cysts (c) are seen. A total of 16 cysts were seen in both kidneys. This appearance is classic for ADPKD seen in adults.

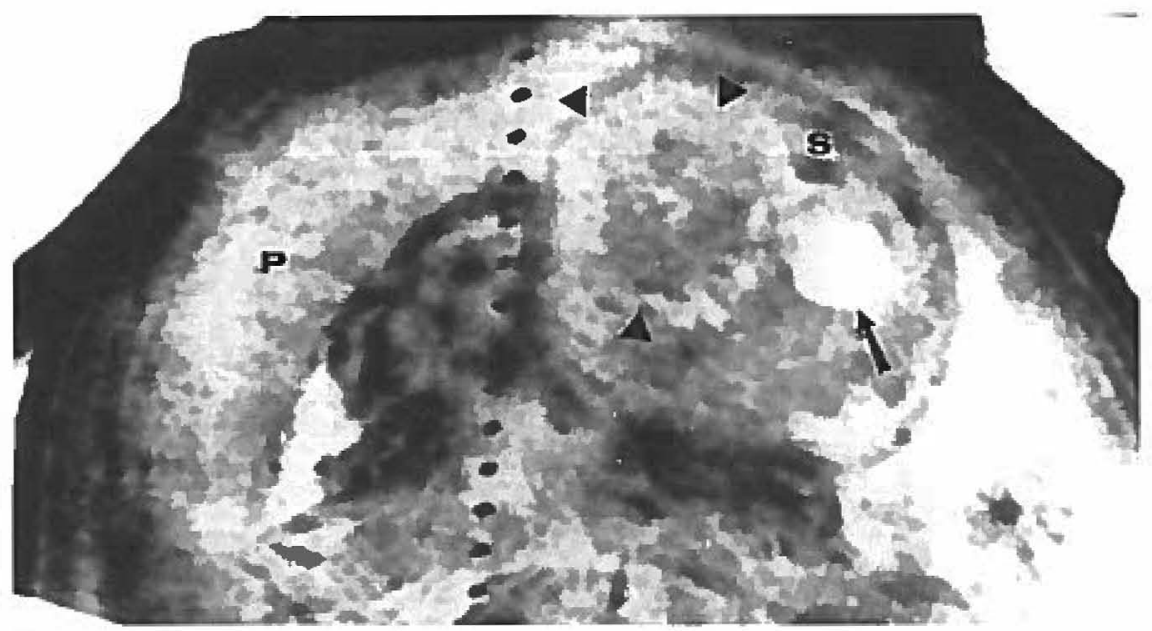

A

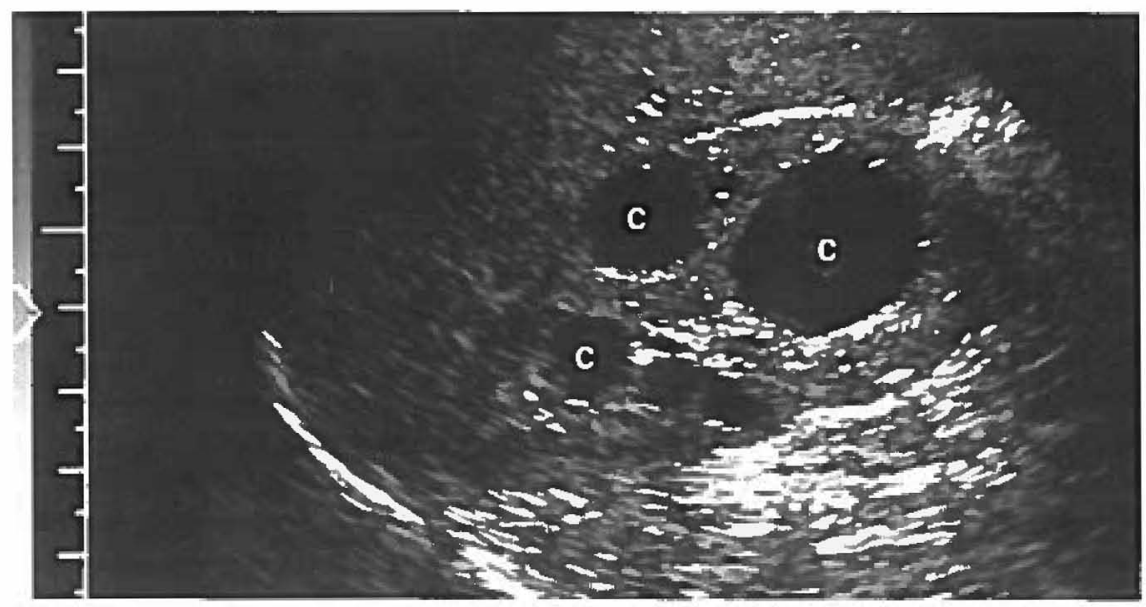




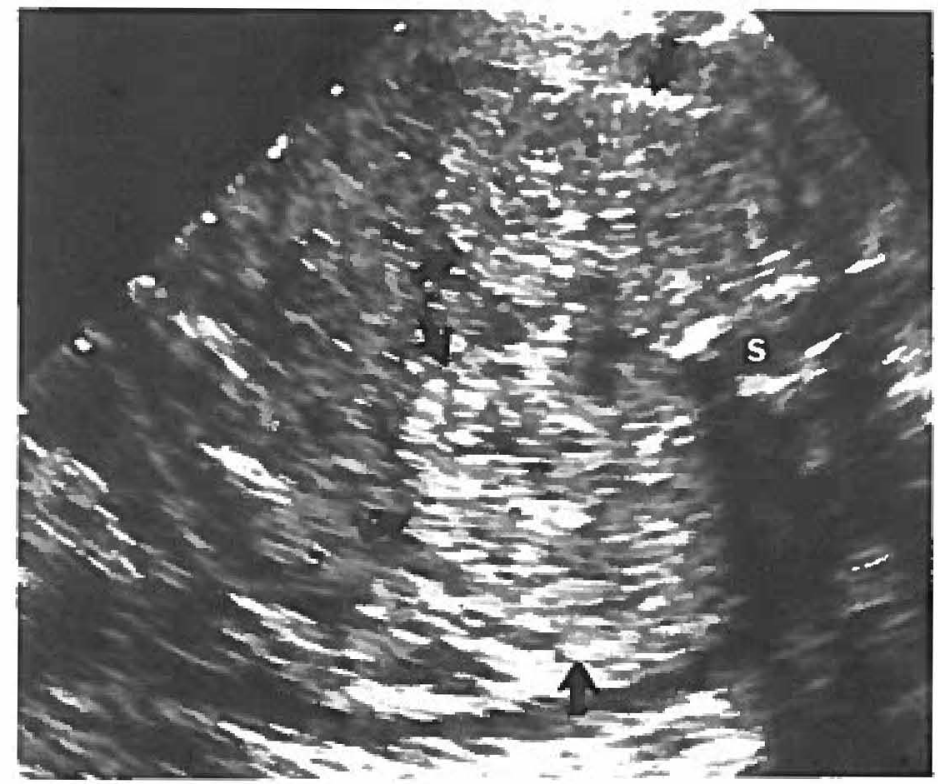

A

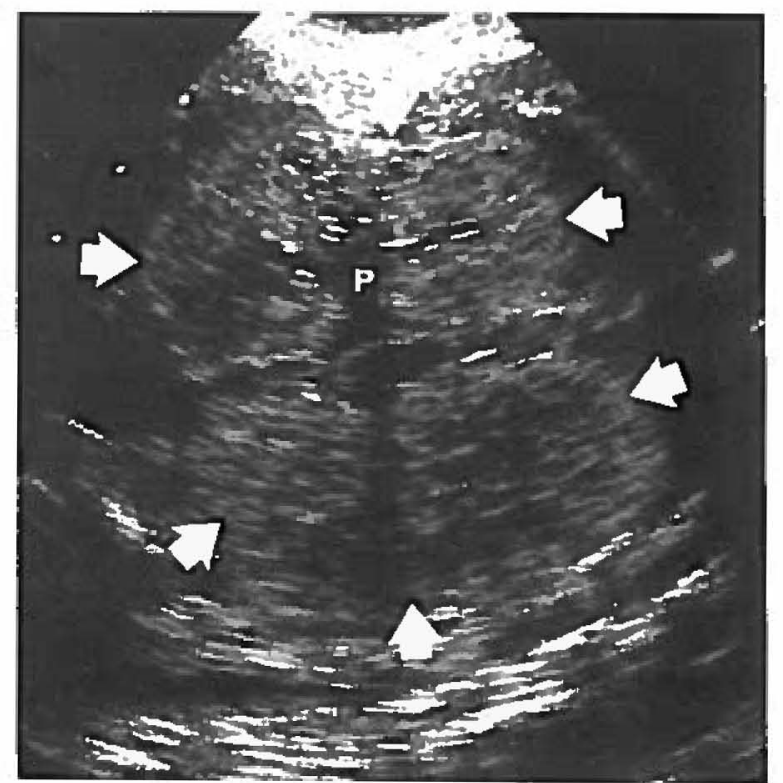

B

Figure 2 Case 2. ADPKD. Transverse (A) and longitudinal (B) scans through the fetal kidneys at $231 / 2$ weeks' gestational age. The kidneys (arrows) are enlarged and echogenic. No cysts were seen. Autopsy revealed enlarged kidneys compatible with ADPKD. The renal pelvis (P) can be seen. The spine (S) is noted.

kidneys, a typical appearance for ADPKD (Fig. 1B). The child was asymptomatic with normal renal function and a negative urinalysis at that time. Blood pressure was at the upper limits of normal; however, no antihypertensive treatment had been rendered for the past year.

Case 2 This fetus is a younger sibling of the child presented in Case 1 . An obstetrical ultrasound conducted at $231 / 2$ weeks demonstrated enlarged, echogenic kidneys (Fig. 2). Right and left kidney measured $3.8 \mathrm{~cm}$ in length (normal, $2.5 \pm 0.3 \mathrm{~cm}$ ). No renal or liver cysts were seen. The amniotic fluid was slightly decreased; however, no other congenital anomalies were visualized. A repeat antenatal ultrasound was performed 6 days later confirming the findings of the first examination. A therapeutic abortion was conducted shortly after the sonogram. On gross pathology the kidneys were enlarged, each weighing $20 \mathrm{~g}$. The medulla contained numerous dilated ducts or tubule-like cystic structures of variable size. The microscopic findings were found to be consistent with ADPKD or medullary cystic disease.

Case 3 A premature infant was delivered at 32 weeks' gestational age secondary to premature labor. Oligohydramnios was noted at birth. Potter's facies and moderate pulmonary hypoplasia were present. The abdomen was markedly distended with bilateral masses.

A neonatal ultrasound was performed at $2 \mathrm{~h}$ of age demonstrating enlarged kidneys with multiple small cysts. The right kidney measured $9.3 \mathrm{~cm}$ in length, the left $10.1 \mathrm{~cm}$ in length. No liver cysts were present. The infant died at $4 \mathrm{~h}$ of age of respiratory distress after extubation. Pathology revealed mas- sively enlarged kidneys with variable sized cysts involving all portions of the nephron, classic of ADPKD.

Following postmortem diagnosis of ADPKD in this infant, both parents were scanned and the father was found to have multiple variable sized cysts consistent with ADPKD and the

Figure 3 Case 5. ADPKD. Longitudinal scan through the fetal right kidney at 31 weeks' gestational age. The kidney (arrows) is enlarged and echogenic. No cysts are seen. The collecting system is seen centrally.

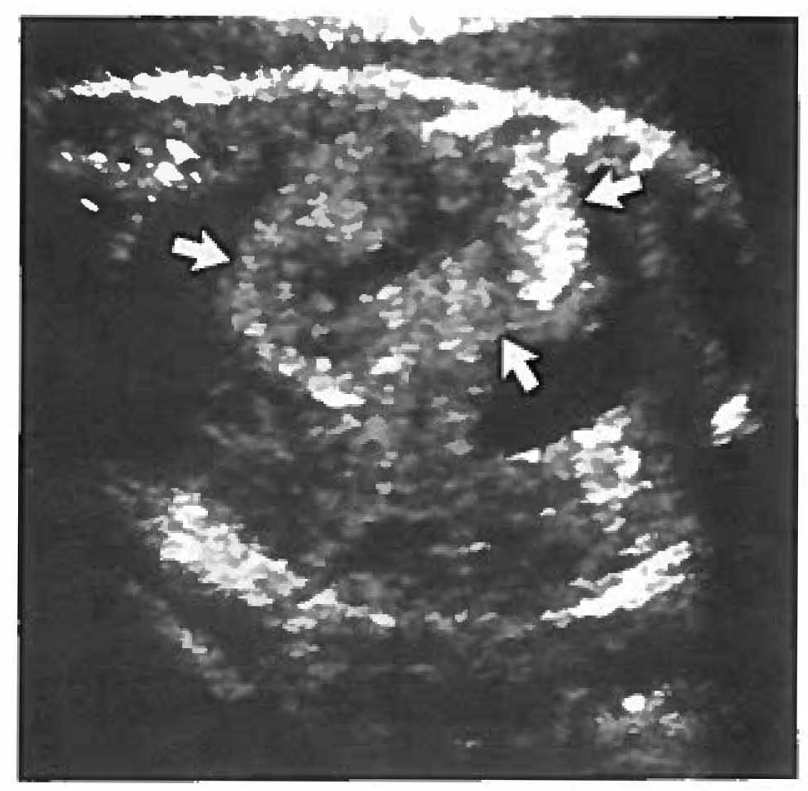


Table 1: Ultrasonographic Appearance of ADPKD in the Fetus and Young Infant

\begin{tabular}{|c|c|c|c|c|c|c|}
\hline $\begin{array}{l}\text { Case } \\
\text { No. }\end{array}$ & $\begin{array}{c}\mathrm{GA} \\
\text { (weeks) }\end{array}$ & Antenatal & Age & Neonatal & Age & Childhood \\
\hline \multicolumn{7}{|c|}{ Present cases } \\
\hline 1 & 36 & $\begin{array}{l}\text { Enlarged, echogenic } \\
\text { kidneys, cyst left } \\
\text { upper pole }\end{array}$ & 8 days & $\begin{array}{l}\text { Enlarged, echogenic } \\
\text { kidneys, cyst left } \\
\text { upper pole }\end{array}$ & 4 yr, 10 mo & $\begin{array}{l}\text { Enlarged, with } \\
\text { multiple } \\
\text { bilateral cysts }\end{array}$ \\
\hline 2 & $23^{1 / 2}$ & $\begin{array}{l}\text { Enlarged, echogenic } \\
\text { kidneys, no cysts }\end{array}$ & & & & \\
\hline 3 & & & $2 \mathrm{hr}$ & $\begin{array}{l}\text { Enlarged, echogenic } \\
\text { kidneys, multiple } \\
\text { small cysts }\end{array}$ & & \\
\hline 4 & 13,31 & Normal exam & 25 days & $\begin{array}{l}\text { Normal kidneys, } \\
\text { normal echogenicity, } \\
2 \text { cortical cysts }\end{array}$ & & \\
\hline 5 & $\begin{array}{l}31,35,37 \\
38+\end{array}$ & $\begin{array}{l}\text { Enlarged, echogenic } \\
\text { kidneys, no cysts }\end{array}$ & 1 day & $\begin{array}{l}\text { Enlarged, echogenic } \\
\text { kidneys, few cortical } \\
\text { cysts }\end{array}$ & & \\
\hline \multicolumn{7}{|l|}{ Loh et $\mathrm{al}^{4}$} \\
\hline 6 & & & $3 \mathrm{mo}$ & $\begin{array}{l}\text { Enlarged, echogenic } \\
\text { kidneys, no cysts }\end{array}$ & & \\
\hline 7 & & & $3 \mathrm{mo}$ & $\begin{array}{c}\text { Enlarged, echogenic } \\
\text { kidneys, no cysts }\end{array}$ & & \\
\hline \multicolumn{7}{|c|}{ Fellows et al ${ }^{6}$} \\
\hline 8 & & & 4 days & $\begin{array}{l}\text { Enlarged mass with } \\
\text { cysts, echogenicity } \\
\text { N/A }\end{array}$ & & \\
\hline \multicolumn{7}{|c|}{ Hayden et al ${ }^{5}$} \\
\hline 9 & & & $\begin{array}{r}\text { Shortly } \\
\text { after } \\
\text { birth }\end{array}$ & $\begin{array}{c}\text { Enlarged, echogenic } \\
\text { kidneys, no cysts }\end{array}$ & & \\
\hline \multicolumn{7}{|c|}{ Chevalier et $\mathrm{al}^{3}$} \\
\hline 10 & & & 15 days & $\begin{array}{l}\text { Enlarged, echogenicity } \\
\text { N/A, no cysts }\end{array}$ & & \\
\hline \multicolumn{7}{|l|}{ Main et al7 } \\
\hline 11 & 21,36 & $\begin{array}{l}\text { Normal exam, normal } \\
\text { size kidneys, bilateral } \\
\text { multiple renal cysts, } \\
\text { echogenicity N/A }\end{array}$ & & & & \\
\hline 12 & $16,22,30$ & $\begin{array}{l}\text { Normal exam, } \\
\text { enlarged, echogenic } \\
\text { kidneys, no cysts }\end{array}$ & & & & \\
\hline \multicolumn{7}{|c|}{ Zerres et al ${ }^{\mathrm{B}}$} \\
\hline 13 & 33 & $\begin{array}{l}\text { Enlarged, echogenic } \\
\text { kidneys }\end{array}$ & & & & \\
\hline
\end{tabular}

GA, gestational age.

mother had normal renal architecture. Previously the diagnosis had been unsuspected in the father. Upon review of family history, the fraternal grandmother was found to have ADPKD.

Case 4 A premature infant of $\mathbf{3 1}$ weeks' gestational age was delivered by $\mathrm{C}$-section to a mother with ADPKD. Antenatal ultrasounds were performed at 13,27, and 31 weeks' gestational age. The kidneys appeared normal in size and echogenicity. The amniotic fluid was normal in amount and a bladder was present. A neonatal ultrasound performed at 25 days of age showed normal sized kidneys with two cortical cysts. Liver cysts were not seen on the antenatal or neonatal ultrasound. Renal function was normal at birth. At 25 months of age renal function was impaired with the blood urea nitrogen and creatinine of $28 \mathrm{mg} / \mathrm{dl}$ and $3.4 \mathrm{mg} / \mathrm{dl}$, respectively; the ultrasound scan was technically poor and no cysts were detected.

Case 5 Antenatal ultrasounds were performed at $31,35,37$, and $38+$ gestational weeks of age. The father had multiple 
renal cysts by ultrasound, an appearance compatible with ADPKD. The scan at 31 weeks revealed enlarged, echogenic fetal kidneys, the right measuring $7 \mathrm{~cm}$ in length, and the left $6 \mathrm{~cm}$ in length (normal, $3.4 \pm 0.5 \mathrm{~cm}$ ) (Fig. 3). No cysts were seen in the kidneys or liver. The amniotic fluid was slightly decreased on the first examination; however, on follow-up examinations the amount of fluid was normal. The follow-up antenatal examinations confirmed the abnormal appearance of the kidneys. A bladder was present on all of these antenatal examinations.

At birth no other apparent abnormalities were present. The renal function was normal. A neonatal ultrasound was performed on the first day of life. It showed enlarged, echogenic kidneys with several $2-3 \mathrm{~mm}$ cysts. No tiver cysts were present. At 8 months of age, the infant was clinically stable with normal renal function. A follow-up ultrasound has not been performed.

\section{RESULTS}

The sonographic appearance of ADPKD in the fetus and young infant are given in Table 1 . Eleven of 13 cases had renal enlargement. In only 10 cases was echogenicity reported, and nine of these 10 had increased echogenicity of the renal parenchyma. Six of the 13 cases had cysts large enough to be detected by ultrasound. Three cases in our series had antenatal and neonatal sonograms: progression of cyst formation, with an increase

Table 2: Follow-Up

\begin{tabular}{|c|c|c|c|}
\hline $\begin{array}{l}\text { Case } \\
\text { No. }\end{array}$ & Age & $\begin{array}{l}\text { Renal } \\
\text { Function }\end{array}$ & $\begin{array}{l}\text { Blood } \\
\text { Pressure }\end{array}$ \\
\hline \multicolumn{4}{|l|}{ Present cases } \\
\hline 1 & $4 \mathrm{yr} 10 \mathrm{mo}$ & Normal & $\begin{array}{l}\text { Upper limits } \\
\text { of normal }\end{array}$ \\
\hline 2 & $\operatorname{TAB}(231 / 2)$ & N/A & N/A \\
\hline 3 & Death $4 \mathrm{hr}$ & $N / A$ & N/A \\
\hline 4 & $25 \mathrm{mo}$ & Decreased ${ }^{*}$ & $N / A$ \\
\hline 5 & $8 \mathrm{mo}$ & Normal & Normal \\
\hline \multicolumn{4}{|l|}{ Loh et al } \\
\hline 6 & $6 \mathrm{mo}$ & Normal & Normal \\
\hline 7 & $6 \mathrm{mo}$ & Normal & Normal \\
\hline \multicolumn{4}{|l|}{ Fellows et al } \\
\hline 8 & $8 \mathrm{mo}$ & Decreasedt & Increased \\
\hline $\begin{array}{l}\text { Hayden et al } \\
9\end{array}$ & $1 \mathrm{yr}$ & Normal & Normal \\
\hline $\begin{array}{l}\text { Chevalier et al } \\
10\end{array}$ & Death 1 mo & $N / A$ & N/A \\
\hline $\begin{array}{l}\text { Main et al } \\
11 \\
12\end{array}$ & $\begin{array}{l}2 \mathrm{mo} \\
6 \mathrm{mo}\end{array}$ & $\begin{array}{l}\text { Normal } \\
\text { Normal }\end{array}$ & $\begin{array}{l}\text { Normal } \\
\text { Normal }\end{array}$ \\
\hline $\begin{array}{l}\text { Zerres et al } \\
\quad 13\end{array}$ & $1 \mathrm{yr}$ & Normal & N/A \\
\hline
\end{tabular}

- $\mathrm{BUN}=28$; creatinine $=3.4$.

$t$ "high BUN and serum creatinine."

$\mathrm{TAB}$, therapeutic abortion. in the size and number of cysts, was seen in all three cases. In one of these cases, the fetal kidneys were normal on the antenatal sonogram, and two cortical cysts were later apparent on the neonatal sonogram at 25 days of age.

Analysis of family history in the 13 cases reviewed revealed that in every case, one parent had ADPKD. In six of the 13 cases, the positive parent was unaware of his or her disease until after diagnosis of the affected child. In two of the 13 cases, the diagnosis of ADPKD in the mother was made incidentally during antenatal sonography of an affected fetus. The remaining five parents were aware of their disease prior to the birth of the affected infant.

Data regarding clinical outcome are given in Table 2. Ten of the 13 fetuses and young infants are alive, with eight of 10 having normal renal function at the time of follow-up. Two of the 10 living infants had decreasing renal function. Three of the 13 cases were dead, one from sepsis, one from respiratory distress associated with hyaline membrane disease, and one therapeutic abortion was performed at $231 / 2$ gestational weeks. The age at the time of follow-up ranged from 2 months to 4 years 10 months.

\section{DISCUSSION}

The appearance of the kidneys is widely variable in the fetus and young infant with ADPKD (Table 1). Renal enlargement $(85 \%)$ was the most common and most helpful sonographic finding. Approximately $50 \%$ of the patients already had cysts large enough to detect by ultrasound in the fetal or young infant period. In our series of five patients, progression of cyst formation in size and/or number was seen in three cases. Increased renal echogenicity was suggested in nine of 10 cases. Though increased echogenicity is a rather subjective finding, it is important and should be present in the fetus and young infant. Increased echogenicity has been reported in infantile polycystic kidney disease, fetal renal dysplasia, and medical renal disease. ${ }^{21-23}$

The diagnosis of ADPKD has been made antenatally by ultrasound in six fetuses; the earliest diagnosis was made at $231 / 2$ weeks, allowing for termination. The diagnosis may not always be made this early; in two cases, normal sonograms in the second trimester became abnormal in the third trimester.

Potter describes ADPKD (Type III) as the only variety of cystic disease to involve the collecting tubule as well as the nephron; in addition, normal and abnormal nephrons are intermixed. ${ }^{24}$ The ampulla, the advancing portion of the ureteral bud, stimulates tubule division and nephron induction. Potter felt that ampullary injury resulted in the cystic changes. The timing of the insult as 
well as the severity of the insult determine the extent of ampullary injury which, in turn, determines the degree to which renal function is impaired. The variability in ampullary injury produces a spectrum of disease, with severe disease resulting in early cyst formation, poor renal function, and possible death in infancy. The opposite end of the spectrum is mild involvement with survival into old age. ${ }^{24}$ The pathologic findings of ADPKD in a 14-week fetus suggests that the anomaly responsible for the production of cysts is present from nephrogenesis and that it is not secondary to an acquired insult. ${ }^{3.15}$

The pathology without the family and clinical history may be confusing. Potter stated that in ADPKD different portions of the kidney may vary in appearance, especially in the infant. Numerous small cysts or variably sized cysts may be scattered throughout the parenchyma. Individual portions of the kidney may be exclusively cystic or contain no cysts. Occasionally the pathologic appearance can be very similar to medullary sponge kidney with large or small cysts involving the papilla, as in Case 2. In addition, the changes in children can be identical to those in the adult (Case 3) except for increasing size of cysts with age. ${ }^{24}$

The differential diagnosis for renal cystic disease in the fetus and newborn ${ }^{3-18}$ should include ADPKD, autosomal recessive PKD, trisomy syndromes (e.g., 13, 18, and triploidy), Sturge-Weber syndrome, Zellweger syndrome, Lawrence-Moon-Biedl syndrome, tuberous sclerosis, and Jeune's syndrome. The variation in renal presentation of ADPKD emphasizes the difficulty in diagnosing it from the sonogram alone. ADPKD can be difficult or impossible to distinguish sonographically from autosomal recessive (infantile type) polycystic kidney disease; certainly differentiation of these two diseases is critical since the prognosis for ADPKD is much better than for autosomal recessive PKD. Like ADPKD, the sonographic appearance of autosomal recessive PKD is quite variable. The classic sonographic appearance in this recessive type of renal cystic disease is that of enlarged kidneys with increased echogenicity of the renal parenchyma. Cysts are rarely seen. The renal borders are usually poorly defined. ${ }^{21}$ The appearance of a definite renal anomaly in a fetus at risk for a specific congenital renal disease indicates occurrence of the disease. ${ }^{25}$

A family history of ADPKD is a critical element in making the diagnosis of ADPKD in the fetus or neonate. Renal cystic disease diagnosed in the fetus or neonate should lead to the investigation of the family history and family screening. Ultrasound is the imaging method of choice for family screening. ${ }^{26}$ Although every case in this review had one parent affected with ADPKD, only five of $13(38 \%)$ were aware of their disease prior to their pregnancy. Seventy-five percent of ADPKD is not recognized clinically and is detected only at postmortem examination. ${ }^{27}$ Genetic counseling in families with
ADPKD is a difficult problem since the clinical diagnosis is usually made in the third and fourth decade of life, well into the reproductive years. ${ }^{28}$ Establishing the diagnosis of ADPKD in the fetus or neonate could have important implications in the future family planning of a parent unaware of his or her own disease, as well as in the genetic counseling of the child, ${ }^{3,18}$

Antenatal ultrasound should be considered in all fetuses at risk for ADPKD. Historically it was thought that this autosomal dominant type of renal cystic disease presented only in the adult. ${ }^{24}$ Increased awareness that ADPKD does occur in utero will result in increased detection of this disease in the fetus. The early detection of ADPKD allows for proper clinical care. The antenatal diagnosis of the disease gives the parents more information regarding prognosis and possible termination of pregnancy, if the diagnosis is made in the second trimester.

Prognoses and definite conclusions cannot be determined from the relatively short follow-up in the limited number of cases reviewed in this paper. The prognosis is certainly not uniformly lethal, and in fact may be reasonably favorable. In fact, 10 of the 12 fetuses and young infants (one therapeutic abortion excluded) were alive and eight of 10 had normal renal function at the time of follow-up (range, 2 months to 4 years, 10 months). Indeed, two infants had died, one secondary to sepsis and one from hyaline membrane disease, probably related to prematurity ( 32 weeks' delivery) and pulmonary hypoplasia. Unfortunately, oligohydramnios complicated the latter case, and it is unknown whether it contributed to the death. In general, when oligohydramnios is seen in the setting of fetal renal disease, pulmonary hypoplasia may occur, and it definitely does affect neonatal outcome.

\section{CONCLUSION}

ADPKD does occur in the fetus and young infant and should be part of the differential consideration in a fetus and young infant with renal cystic disease. ADPKD in the fetus and young infant usually presents ultrasonographically with nephromegaly and increased echogenicity of the renal parenchyma. Cysts may or may not be present initially, but they usually increase in size and number with increasing age. Renal cystic disease diagnosed in the fetus and young infant should trigger an investigation of the family history and sonographic screening. Antenatal sonography should be considered in all fetuses at risk for ADPKD. Early diagnosis of ADPKD allows for proper clinical care and genetic counseling of the affected infant, as well as parents of the affected infant. The prognosis of the fetus and young infant with ADPKD evaluated by ultrasound is uncertain secondary to the small numbers of cases and the 
short period of time over which they were followed. It does not appear to be universally lethal, and may in fact be associated with a reasonably favorable prognosis. More follow-up is necessary before more definitive conclusions can be reached.

\section{ACKNOWLEDGMENTS}

This research was supported by grant 1 POI AM 34039, Human Polycystic Kidney Disease (PKD), awarded by the Department of Health and Human Services, Department of Health Services, NIADDK.

We would like to thank Dr. Faye Laing, University of California, San Francisco; Dr. Donald Newman, British Columbia Children's Hospital; and Dr. Gloria Komppa, Fitzsimons Army Medical Center, for contributing cases to this series.

\section{REFERENCES}

1. Chester AC, Argy WP: Polycystic kidney disease: Diagnosis and management. South Med J 72:1582, 1979

2. Madewell JE, Hartman DS, Lichtenstein JE: Radiologicpathologic correlations in cystic disease of the kidney. Radiol Clin North Am XVII:261, 1979

3. Chevalier RL, Garland TA, Buschi AJ: The neonate with adult type autosomal dominant polycystic kidney disease. Int J Pediatr Nephrol 2:73, 1981

4. Loh JP, Haller JO, Kassner EG, Aloni A, Glassberg K: Dominantly-inherited polycystic kidneys in infants: Association with hypertrophic pyloric stenosis. Pediatr Radiol 6:27, 1977

5. Hayden KC, Swischuk LE, Davis M, Brouhard BH: Puddling: A distinguishing feature of adult polycystic kidney disease in the neonate. AJR 142:811, 1984

6. Fellows RA, Leonidas JC, Beatty EC Jr: Radiologic features of "adult type" polycystic kidney disease in the neonate. Pediatr Radiol 4:87, 1976

7. Main D, Mennuti MT, Cornfeld D, Coleman B: Prenatal diagnosis of adult polycystic kidney disease. Lancet 2:337, 1983

8. Zerres K, Weiss H, Bulla M, Roth B: Prenatal diagnosis of an early manifestation of autosomal dominant adult-type polycystic kidney disease. Lancet 2:988, 1982

9. Mehrizi A, Rosenstein B], Pusch A, Askin JA, Taussig HB: Myocardial infarction and endocardial fibroelastosis in children with polycystic kidneys. Bull Johns Hopkins Hosp 115:92, 1964

10. Ross DG, Travers H: Infantile presentation of adult-type polycystic kidney disease in a large kindred. J Pediatr 87:760, 1975
11. Bengtsson U, Hedman L, Svalander C: Adult type of polycystic kidney disease in a new-born child. Acta Med Scand 197:447, 1975

12. Shokeir MH: Expression of "adult" polycystic renal disease in the fetus and newborn. Clin Genetics 14:61, 1978

13. Eulderink F, Hogewind BL: Renal cysts in premature children. Arch Pathol Lab Med 102:592, 1978

14. Stickler GB, Kelalis PP: Polycystic kidney disease: Recognition of the "adult form" (autosomal dominant) in infancy. Mayo Clin Proc 50:547, 1975

15. Blyth H, Ockenden BG: Polycystic disease of kidneys and liver presenting in childhood. J Med Genetics 8:257, 1971

16. Anton PA, Abramowsky CR: Adult polycystic renal disease presenting in infancy: A report emphasizing the bilateral involvement. J Urol 128:1290, 1982

17. Kaye C, Lewis PR: Congenital appearance of adult-type (autosomal dominant) polycystic kidney disease. J Pediatr $85: 807,1974$

18. Proesmans W, Van Damme B, Casaer P, Marchal G: Autosomal dominant polycystic kidney disease in the neonatal period: Association with a cerebral arteriovenous malformation. Pediatrics 70:971, 1982

19. Lawson TL, Foley WD, Berland LL, Clark KE. Radiology 138:153, 1981

20. Han BK, Babcock DS: Sonographic measurements and appearance of normal kidneys in children. AJR 145:611, 1985

21. Boal DK, Teele RL: Sonography of infantile polycystic kidney disease. AJR 135:575, 1980

22. Mahony BS, Filly RA: Fetal renal dysplasia. Radiology 152:143, 1984

23. Scheible W, Talner LB: Gray scale ultrasound and the genitourinary tract. Radiol Clin North Am XVIl:281, 1979

24. Potter EL: Normal and Abnormal Development of the Kidney. Chicago, Year Book Medical Publishers, 1972, pp 182-208

25. Mahony BS, Callen PW, Filly RA, Golbus MS: Progression of infantile polycystic kidney disease in early pregnancy. J Ultrasound Med 3:277, 1984

26. Rosenfield AT, Lipson MH, Wolf B, Taylor KJW, Rosenfield NS, Hendler E: Ultrasonography and nephrotomography in the presymptomatic diagnosis of dominantly inherited (adult-onset) polycystic kidney disease. Radiology $135: 423,1980$

27. Higgins CC: Bilateral polycystic kidney disease: Review of 94 cases. Arch Surg 65:318, 1952

28. Hogewind BL, Veltkamp JJ, Koch CW, De Graeff J: Genetic counselling for adult polycystic kidney disease. Ultrasound a useful tool in pre-symptomatic diagnosis? Clin Genetics 18:168, 1980 